\title{
On Guided Imagery and Music (GIM) as Both Part of Music Therapy and as Separate From it
}

\author{
Martin J Lawes ${ }^{1 \text { * }}$ \\ 1 Integrative GIM Training Programme, UK \\ *martinlawesmt@gmail.com \\ Received: 17 September 2021 Accepted: 24 January 2022 Published: 1 March 2022 \\ Editor: Helen Brenda Oosthuizen Reviewers: Denise Grocke, Kobie Swart
}

\begin{abstract}
Guided Imagery and Music (GIM) can be considered a specialism in which qualified music therapists may train, along with mental health practitioners from other professional backgrounds including psychotherapists, psychologists, and psychiatrists. For this latter group of practitioners, identifying themselves as music therapists, or implying this when describing GIM as a music therapy method in advertising their services, is controversial. It may indeed even be unlawful in countries where music therapy training and practice are regulated by the state.

The situation is a complex and inherently confusing one. This is because on the one hand GIM is an acknowledged international model of music therapy. On the other hand, as a specialism, GIM is distinct from music therapy in both training and practice, with GIM practitioners having various professional backgrounds.

It is proposed that international collaboration and discussion are needed, with recommendations made to foster public confidence based on a clear understanding of who is and is not a qualified music therapist and member of the music therapy profession, and who is qualified to practice what safely and effectively. The article aims to illuminate the issues that may need to be taken into consideration in developing a consensus position.
\end{abstract}

Keywords: Guided Imagery and Music (GIM), Music and Imagery (MI), receptive music therapy, specialisms, advanced practice, scope of practice, competencies

\section{Introduction}

Guided Imagery and Music (GIM) was cited at the Ninth World Congress of Music Therapy as one of "Five International Models of Music Therapy Practice" (Wheeler et al., 2012). GIM research is regularly included in music therapy journals and other music therapy literature. Whilst it might be assumed that all those who are trained in and practice GIM can legitimately claim that they are music therapists practicing a type of receptive music therapy, the matter is not an entirely straight forward one.

The topic is complex at many different levels, with the spectrum of contemporary GIM practice comprising not only the Bonny Method of GIM, but also other GIM and 
Music and Imagery (MI) methods as discussed below (Grocke \& Moe, 2015). There is also no international recognition that those trained in the Bonny Method and its variations (Muller, 2014) become qualified music therapists based on their GIM training alone. Rather, GIM is a specialism (or rather a specialist area of practice) in which those who are already qualified as music therapists can train, as can practitioners from other professional backgrounds. Perhaps because of this, the international GIM organizations which endorse, register, or accredit practitioners do not, at the time of writing, define GIM as a music therapy method or model.

It is nevertheless evident that some European GIM trainers consider GIM training to be training in a type of music therapy, even if it does not lead to qualification as a music therapist. It has even been suggested that the European Association for Music and Imagery (EAMI) re-define the Bonny Method of GIM in part as a music therapy approach (European Association for Music and Imagery, 2021a).

With GIM internationally recognized as a music therapy model, Bonde (2015) discusses what he considers to be a paradoxical situation in Europe:

It [The Bonny Method of GIM] is a truly international model of receptive music therapy, practised in five continents, and yet it is not registered or integrated in the European music therapy community, e.g. as related to the European Music Therapy Confederation (EMTC). (p. 86)

The author's impression is, nevertheless, that GIM is becoming increasingly valued by the music therapy profession as a specialism. Even if the EAMI, as a relatively newly established association, is not yet a member organization of the EMTC as it might potentially be, the EMTC in a Policy Statement do now formally recognize GIM as a specialism for those already qualified as music therapists (European Music Therapy Confederation, 2018). The national music therapy organizations are encouraged by the EMTC to recognize GIM in the same way. The author is strongly supportive of developments such as this which foster the integration of GIM within music therapy.

The difficulty, as discussed, is that it is not only those who are already qualified as music therapists who train in GIM. Thus, what needs to be clarified is whether GIM practitioners from other professional backgrounds should be describing GIM as a type of music therapy in advertising their services and/or whether they should be identifying themselves to be music therapists. It is evident that some are beginning to do these things in Europe, seemingly based on the way the method has been presented during training.

The author's position is that there need be no conflict between fostering the ongoing recognition of GIM as a music therapy specialism on the one hand, and making sure that the public understand clearly that GIM training alone does not qualify practitioners as music therapists on the other hand. The public may become confused about this when practitioners who are not qualified music therapists describe GIM as music therapy in advertising their services. The US-based Association for Music and Imagery (AMI) appear to agree, advising their members:

Bonny Method [of GIM] training is not music therapy training. To avoid confusing the public and misleading their current and potential clients, the AMI strongly advises against non-music therapists (counselors, social workers, psychotherapists, or others) who are trained in the Bonny Method referring to themselves as music therapists or referring to their practices as music therapy. (Association for Music and Imagery, 2021b, pp. 7-8)

The author welcomes these newly published guidelines, where in his view it is the international GIM organizations and GIM trainers who have the prime responsibility in ensuring ethical practice in the presentation of GIM and in advertising services. Given the apparent disparity between the views of some European GIM trainers who discuss and/or promote GIM training as being in a type of music therapy on the one hand (European Association for Music and Imagery, 2021a), and the views of the AMI on the other hand, the author believes international discussion to be needed to agree a consensus position. 
The matter is a complex, multi-faceted one that is as confusing for the GIM community, including trainees, as it is for the wider music therapy community, other professionals, and the public alike. This article aims to contribute to and help inform discussion, where GIM is in some senses a part of music therapy but is also distinct from it in training and in practice.

Before discussing the differences between music therapy and GIM as a specialism, it is necessary first to clarify the complexity of GIM as a field of practice and the author's use of terms.

\section{GIM as a Spectrum of Practice}

In this article, the term GIM, as an abbreviation of Guided Imagery and Music, is used generically (Bruscia, 2015) to encompass the full spectrum of practice developed by those trained in the Bonny Method of GIM. This spectrum includes not only the Bonny Method itself, but also what the AMI (2021a) term "adaptations and modifications" (p. 9) of the method. These adaptations and modifications include other GIM methods along with the simpler Music and Imagery (MI) methods that have been developed, the latter of growing importance in both practice and research (Bonde, 2017; Grocke \& Moe, 2015; Moe and Lund, 2017).

The designation/title GIM therapist is used in a similarly generic way to the term GIM in the article. ${ }^{1}$

\section{The Bonny Method of GIM}

The Bonny Method of GIM, and other GIM methods (as distinct from MI), are generally those that involve the client imaging to music in an expanded (altered, or non-ordinary) state of consciousness. The therapist guides the client's spontaneously evolving imagery process non-directively. In doing so, an interactive dialogue develops. The client describes their experience which the therapist affirms, the therapist asking open questions to support the unfolding of the client's imagery experience across what may be several different sensory modalities. These modalities might include what is seen (mentally visualized) or smelt by the client (with eyes closed, listening to the music in an altered state of consciousness), sounds and voices heard, what is experienced through touch, the experience of warmth or cold, and so on. The client's active embodied emotional involvement in the process as imager is encouraged as is their engagement with the music as co-therapist (Bruscia, 2015).

Traditionally, programmes of recorded music are used in the Bonny Method of GIM, with music chosen that comes from the Western classical tradition. A music programme is generally comprised of between four and eight separate pieces, often individual movements from complete works, the duration of a music programme typically between 30 and 45 minutes. The pieces are carefully sequenced so as to help structure an unfolding imagery experience that can help address therapeutic need. Different music programmes are intended to work with different areas of experience and aspects of need.

Helen Bonny, the music therapist who originally developed GIM in the US in the 1970s, created a set of core music programmes which are still widely used (Grocke, 2019b), though many other programmes have since been developed by GIM practitioners (Grocke, 2019a). Some of the newer programmes feature the music of other genres and traditions, including Chinese music, world music generally, orchestral versions of pop music, contemporary classical music, and jazz (Fuglestad, 2019; Ng, 2019). Whilst GIM music programmes may be used in their original form, practitioners may also adapt them or programme the music more spontaneously in a session according to the unfolding of the client's inner process. 


\section{Adaptations and Modifications}

Adaptations and modifications of the Bonny Method of GIM are identified in the literature employing a wide variety of terms. Some of these are generic terms including "Short GIM" (Grocke \& Moe, 2015) and MI, with each term encompassing its own spectrum of related methods. Bespoke terms are also used to identify specific models or methods that have been developed such as the "Continuum Model of GIM" (Summer, 2015), "Music, Drawing, and Narrative" (Booth, 2010), "Focused Music Imaging" (Dimiceli-Mitran, 2020), "Music Breathing" (Körlin, 2019), and "Short Music Journeys" (Wärja, 2015). Such methods as these, which can be considered independent methods in their own right (Lawes, 2017), are often more suitable for work in healthcare settings than the Bonny Method of GIM itself (Bonde, 2017; Moe and Lund, 2017).

Grocke explains why she conceives contemporary practice to be more a spectrum of different but related methods, than simply the Bonny Method of GIM and its adaptations:

I have a strong sense that GIM is going through a period of development not unlike MT [music therapy] in the 1980's and 1990's, where we had the five music therapy models (celebrated at the World Congress in Washington, 1999), but where each was also evolving into something new [ ... ] I see GIM as being poised on a similar path of growth and expansion [...] I don't particularly like the way we distinguish between the Bonny Method and the 'not the Bonny Method' way of thinking. I prefer to think of what we do as being on a spectrum [...] [with contemporary research reflecting how] the Bonny Method is evolving into more discrete forms of therapy practice. (Grocke, as quoted in Montgomery, 2015)

Beyond the specific models or methods that have been developed and named, there is no international consensus about the use of generic terms to sub-categorise types of practice within GIM. The use of such terms as Short GIM and MI is indeed inconsistent in the literature with alternative terms also employed within the context of the ongoing developments in the field discussed by Grocke (as cited in Montgomery, 2015). For the purposes of this article, the author will clarify his usage of Short GIM and MI in a way that is broadly consistent with Grocke \& Moe, $2015{ }^{2}$

\section{Short GIM}

In Short GIM, the procedure adopted in the Bonny Method of GIM is modified. The main difference is that that there are typically between five and fifteen minutes of music only, with other elements of the session potentially shortened as well (Grocke \& Moe, 2015). In Summer's (2015) Continuum Model, which integrates different methods and levels of practice, two types of Short GIM are employed. These are "Supportive GIM" (p. 345) which is resource-oriented, and "Re-educative GIM" (p. 346) which is oriented towards addressing specific emotional difficulties or conflicts. The intention is for the client to remain focused on a single emotion and the associated imagery content. A short sequence of music is used to facilitate a process of deepening and integration, where individual music selections may be repeated.

In the Bonny Method of GIM, which Summer (2015) considers a reconstructive ${ }^{3}$ method in her model, the process is a more freely evolving one oriented towards deeper unconscious exploration, transformation, and transcendence. The music programme employed (whether an existing or a spontaneously created one) is likely to feature a complex unfolding musical narrative, generating a correspondingly complex unfolding imagery process featuring many different emotions and images. The different types of GIM in Summer's model (supportive, re-educative, and reconstructive) can thus be understood to address different levels of need and provide a correspondingly different type of experience for the client--a more focused one on the one hand, or a more freely evolving one on the other hand. 


\section{Group GIM}

Group GIM has many similarities with individual work. Here the main difference is that the verbal interaction during the music listening takes place either between the therapist and group members, or amongst the group members alone (Grocke \& Moe, 2015).

\section{Music and Imagery (MI)}

MI methods, whether in individual or group work, are differentiated from the GIM methods in that they do not involve the non-directive guiding and verbal dialogue which are a core feature of the GIM methods. The client's imagery experience is unguided (Grocke and Moe, 2015). Whilst in MI the client may be in an expanded state of consciousness (see examples included in Grocke and Moe, 2015), MI methods have also been developed where the client engages in drawing or other expressive arts whilst listening to the music in an ordinary state of consciousness (Booth, 2010; Dimiceli-Mitran, 2020 ${ }^{4}$; Summer, 2015).

MI sessions are usually of shorter duration than the 1.5-2 hours needed for a Bonny Method of GIM session. The work is typically, though not always, resource-oriented, often using a single piece of music or a short sequence of music of between five- and fifteen-minutes duration. Both individual and group work may be undertaken (Grocke and Moe, 2015).

There may be an especial emphasis on the collaboration of client and therapist in MI. In "Supportive Music and Imagery" (SMI) (Paik-Maier, 2017; Summer, 2015, p. 343) that is a part of Summer's Continuum Model, for example, the client is helped to choose the music used which may come from their own collection or the therapist's ${ }^{5}$, the music potentially of diverse genres and traditions. Adaptations and modifications generally employ a wider variety of musical genres than are used in the Bonny Method of GIM, including easy listening, new age, contemporary and film music (Grocke and Moe, 2015).

Bruscia defines the Bonny Method of GIM to include not only the type of individual work described above but also the group form developed by Bonny. Bonny referred to this as either "Group GIM" or "Music and Imagery" (as cited in Bruscia, 2015, p. 16). However, Bonny Method work of this type does not include interactive guiding/dialogue. Thus, according to Grocke and Moe's (2015) definition being followed by the author, Bonny's groupwork method is a type of "Group Music and Imagery" (p. 6). This needs to be differentiated from Group GIM involving dialogue as referred to above.

\section{Addressing Diverse Needs in a Safe, Effective, and Flexible Way: The Use of an Evolving Spectrum of Methods in Contemporary Practice}

Both GIM and MI may be applied in individual and groupwork "for purposes of therapy, healing, self-development, personal growth, or spiritual enlightenment" (Bruscia, 2015, p. 16), with the contemporary spectrum of practice developed to address the needs of diverse clients in diverse settings. To ensure work that is safe and effective, there may be different types of need as well as contraindications to consider. Music Breathing (Körlin, 2019), for example, is a systematic method developed to address the needs of clients with complex PTSD, where the Bonny Method of GIM would be contraindicated, at least to begin with. The individual chapters in Guided Imagery \& $M u$ sic (GIM) and Music Imagery Methods for Individual and Group Therapy (Grocke \& Moe, 2015) illustrate the range of methods and applications that have been developed.

Whilst a single MI or GIM method may be employed for all the work with a particular client (or group), different methods may also be used at different stages of work with a single client (or group). In the Continuum Model, for example, either MI or GIM may be employed, and work undertaken using one of these methods that is supportive, re-educative or reconstructive in nature as needed. Indeed, different methods and 
levels of work can potentially be combined within a single session as part of a clientcentred approach that is creative and flexible (Summer, 2015).

\section{GIM Training and the International GIM Associations}

Just as GIM as a field of practice has steadily evolved over the course of several decades, so has GIM training, with training standards developed to help ensure safe and effective practice.

The US-based Association for Music and Imagery (AMI), which is the longest established international GIM organization, endorses trainers and training programmes that meet its published Training Standards (Association for Music and Imagery, 2021a). The AMI has a Code for Ethical Conduct and Standards of Practice, and provides guidelines for Continuing Education.

The Music and Imagery Association of Australia (MIAA) registers GIM therapists who have completed a MIAA approved GIM training programme. The MIAA also has a Code of Ethics including a grievance procedure (Music and Imagery Association of Australia, 2020).

Apart from the AMI, the only international GIM organization to have published GIM Training Standards is the EAMI (European Association of Music and Imagery, 2019). The organization endorses training programmes that meet its standards and accredits GIM therapists and trainers.

\section{GIM Training Standards and Scope of Practice}

GIM training is typically undertaken as training in a specialism (or advanced method of practice) by those who are already qualified as music therapists on the one hand, or who are qualified mental health counsellors, psychotherapists, psychologists, psychiatrists or similar on the other hand. Whilst the EAMI require such previous therapeutic training and experience as a pre-requisite for GIM training, ${ }^{6}$ the AMI Training Standards (2021a) require that trainees must "have or be in the process of obtaining all necessary additional training to practice as credentialed mental health practitioners, ${ }^{7}$ in their own countries" (p. 12). The AMI describe this as being necessary to ensure "legal legitimacy" and to provide "added clinical expertise" in undertaking the "depth work" that GIM involves (Association for Music and Imagery, 2005, p. 5).

The AMI and EAMI Training Standards are competency-based, setting out the knowledge and skills required of a professional GIM practitioner. The EAMI Standards embrace the full range of contemporary practice including MI, reflecting the importance of this in Europe (Bonde, 2017; Moe and Lund, 2017). The AMI Training Standards, in contrast, only cover practice in the Bonny Method of GIM at present. Trainers may, nevertheless

require additional training in related techniques that are not covered in these Standards. Such techniques may include applications geared towards short experiences using many genres of music for both individuals and groups in a variety of settings. These techniques are neither to be confused with nor named The Bonny Method. Teaching methodologies, supplementary content, and resource materials are left to the discretion of the Primary

Trainer. (Association for Music and Imagery, 2021a, p. 1)

Though all practitioners are taught the principles of adapting and modifying the method according to client need, ${ }^{8}$ endorsed training programmes will differ in relation to the specific Short GIM and MI methods which may or may not be taught. Correspondingly, practitioner's scope of practice--what they are trained to do safely and effectively-will vary to some extent amongst those qualified as GIM therapists.

Because those who train in GIM come from different professional backgrounds, the situation is an especially complex one. The extent of a GIM practitioner's overall scope of practice will depend both on the knowledge and skill base associated with their original training which GIM training extends, and on whatever GIM and MI methods they may have been taught in addition to the Bonny Method of GIM. Therapists may 
also integrate elements of the different methods in which they have been trained, for instance Eye Movement Desensitization \& Reprocessing (EMDR) and GIM, or music therapy improvisation and GIM.

Another factor is that separate training in MI is now increasingly available, with the EAMI developing training standards for this (European Association for Music and Imagery, 2021a; Frohne-Hagemann, 2021). With some GIM training programmes, MI training can be undertaken as complete in itself, whilst at the same time it represents the first or foundational stage of training in GIM for those wanting to pursue this, where the main focus is usually on the Bonny Method of GIM. For practitioners trained in MI alone (who do not pursue further training), their scope of practice will be more limited, with a designation such as MI Therapist more appropriate than GIM Therapist.

\section{GIM Competencies}

Broadly considered, the competencies required for safe and effective practice in the Bonny Method of GIM (and similarly with other GIM and MI methods), can be clarified as they relate to the different phases of a therapy session, each phase having its associated knowledge and skill set.

1. The prelude or pre-music discussion

Verbal skills are required to facilitate a discussion about the client's current concerns and identify a focus for the session. An understanding of both conscious and unconscious processes and communication are needed. However, in GIM the client's issues are not addressed in the way they are in verbal therapy. Rather, the verbal components of the session serve to prepare for, and afterwards to help the client process the therapeutic music and imagery experience.

2. The relaxation induction and focus

This involves the therapist supporting the client to enter an altered state of consciousness ready for the central music and imagery experience that follows. GIM therapists learn how do use different types of relaxation procedure for different therapeutic purposes, how to match induction and music, and how to suggest an imagery focus, which could potentially be of many different types, related to the agreed aim of the session.

3. Music travel

This is the central music and imagery experience. The knowledge and skills required in this part of the session relate to the music, to working with altered states of consciousness, to the guiding, and to the imagery:

a. Music

The therapist needs to have a sophisticated understanding of the nature and function of the recorded music used in GIM, a thorough, experience-based knowledge of the music programmes, the ability to choose a suitable music programme for the client, along with the skills to adapt/swap a programme when necessary and/or to spontaneously programme the music for the client.

b. Altered (or non-ordinary) states of consciousness

The therapist needs a thorough, experience-based understanding of altered states of consciousness, and of how to work safely and effectively with them, understanding the potential risks involved and how to mitigate them (for instance, involving the use of adaptations and modifications).

c. Guiding

The therapist needs to know how to guide the client's music and imagery experience non-directively using verbal and non-verbal interventions. The therapist needs to be able to guide a wide variety of different types of imagery experience. They need to know how to facilitate the deepening of the 
process and the client's active multi-modal engagement in it, and how to facilitate the client's engagement with the music as co-therapist.

d. Imagery

GIM therapists need a comprehensive understanding of imagery; of its metaphorical nature; and of different types, modalities, and levels of imagery, ranging from the personal/psychodynamic, to the mythical/archetypal, to the transpersonal and spiritual. The therapist needs to have a sophisticated, experience-based understanding of imagery processes and associated with this of therapeutic change.

\section{Prelude: Creative and verbal processing}

a. Creative processing

The therapist needs a specialist knowledge of mandala drawing as used in Bonny Method of GIM work. An in-depth understanding of The Great Round of the Mandala (Fincher, 2010) and associated with this of colour and form are also needed. So is an understanding of the function of mandala drawing in GIM.

b. Verbal processing

The therapist needs the specialist skills required to help the client transition from the music and imagery experience, possibly via the creative processing involved in mandala drawing, to verbal processing. The aim is to help the client make sense of and integrate the music and imagery experience and gain insight, with a non-interpretative, client-led stance generally being adopted.

\section{Unique, Advanced Therapeutic Competencies}

Whilst there may be some degree of overlap with a therapist's existing knowledge and skills acquired from their primary therapeutic training, practice in the Bonny Method of GIM requires a highly complex and sophisticated knowledge and skill set of its own that is unique to the type of work that it is. The associated competencies and scope of practice differ substantially from those of both music therapists and verbal therapists, the Bonny Method of GIM not only a specialist but also an advanced method in which already qualified therapists can train (Cohen, 2018).

For music therapists, their original training represents an entry-level qualification to become a member of the music therapy profession. The associated competencies then form the basis for training in the Bonny Method of GIM, which imparts further specialist or advanced competencies. The situation however, is complex, and indeed confusing. This is because as an advanced-level training undertaken also by other professionals, GIM training does not in itself impart the entry level competencies acquired through music therapy training. Thus, in the US, for instance, training in the Bonny Method is

considered advanced training for a music therapist but such training is only one component of achieving advanced competency as a music therapist (AMTA, 2015). Moreover, Bonny Method training certainly does not bestow upon the trainee the professional level of competence in music therapy (AMTA, 2013) that is prerequisite to achieving advanced competence. (Association for Music and Imagery, 2021b, p. 8)

Other professionals need to have acquired the foundational competencies required to train in GIM through their original entry-level qualification as a credentialed mental health or psychotherapeutic practitioner (Association for Music and Imagery, 2021a; European Association of Music and Imagery, 2019).

The unique, advanced-level, specialist therapeutic competencies acquired through training in GIM thus need to be differentiated from the competencies of a qualified music therapist not trained in GIM. Similarly in the case of the competencies of other professionals. 


\section{Music Therapy Training and Competencies}

Those who call themselves music therapists normally have a bachelor's degree or higher in music therapy or an equivalent level qualification in the discipline, dependent on the country in which they trained and on their training programme.

Music therapy training varies from country to country and often from course to course within a country. In general terms, it can be thought of as a training for musicians who learn how to apply, develop, and adapt their existing music skills to work therapeutically with clients in addressing need. Dependent on the training programme and country, there may be various ways in which practitioners are taught how active music-making and creation can be used to foster therapeutic engagement and process where interpersonal relating and/or social participation are central. Active music therapy approaches taught may involve improvisation, songwriting, and/or music performance and arrangement. Music therapists' competencies acquired through training are principally those required to use these active approaches safely and effectively.

Whilst receptive- or listening-based approaches may also be taught, this is typically only at a foundational level ${ }^{9}$ where the techniques learnt need to be differentiated from GIM, which requires specialist training as discussed. Thus, Bruscia (2015) discusses "projection listening" and "relaxation listening" (p. 66) as techniques that "belong within the boundaries of music therapy practice because they evolved prior to and independently of the Bonny Method or GIM, and because they require expertise in music therapy but not necessarily [in] GIM or the Bonny Method" (p. 66).

Other receptive music therapy approaches that are distinct from GIM include song lyric discussion and reminiscence, music appreciation, various methods that involve art media, vibroacoustic therapy, and music and movement (Grocke \& Wigram, 2007). Further receptive music therapy methods practiced in Germany, Denmark, Sweden, and Luxembourg are included in a publication edited by Frohne-Hagemann (2007).

Muller (2014) devotes an entire publication to describing the components which define practice in the Bonny Method of GIM. On this basis, he clarifies the boundaries between the Bonny Method and other GIM practices, and between GIM and receptive music therapy techniques that involve imaging to music. He discusses why it is important to be clear about such boundaries: "Without them, it is unclear who is trained to do what, what practices are potentially harmful when used by the untrained, and what practices can be used safely to benefit patients" (p. 89). In the light of these considerations, characterising GIM as a receptive music therapy method confuses the boundaries between different areas of practice, each requiring different training.

With MI, the situation is especially complex. This is where the scope of practice of qualified music therapists in the US is defined by the American Music Therapy Association (AMTA) and Certification Board for Music Therapists (CBMT) to include "music and imagery":

The music therapy interventions may include music improvisation, receptive music listening, song writing, lyric discussion, music and imagery, singing, music performance, learning through music, music combined with other arts, music-assisted relaxation, musicbased patient education, electronic music technology, adapted music intervention, and movement to music. (AMTA \& CBMT, 2015)

It is important not to confuse the receptive music therapy interventions including music and imagery that lie within the competencies of music therapists (not trained in GIM), with the specialist MI methods developed by GIM practitioners, that are therefore best not identified as receptive music therapy techniques.

The matter has the potential to become even more complex with MI training standards being developed in Europe. These may include standards both for MI methods that "require a psychotherapeutically informed prequalification as required in the EAMI Training Standards," and standards with reduced entry requirements for training in "low-threshold" MI modalities which "do not go into therapeutic depths" (FrohneHagemann, p. 4). This latter proposal is, however, a controversial and problematical 
one in terms of ensuring client safety as is recognized by the EAMI. ${ }^{10}$ In the author's view, whatever standards may in the end be published, the use of terms and associated clarification of professional boundaries and scope of practice will need to be given very careful consideration to avoid confusing trainees, practitioners, other professionals, and the public alike, about who is qualified to do what safely and effectively.

Although GIM is a specialism that requires additional training beyond a music therapist's original qualification, music therapy training programmes (in the UK, for example) increasingly include lectures about GIM, informing trainees about the method as part of the broader field of practice. There are also a few music therapy training programmes internationally where Level I GIM training is included ${ }^{11}$. However, this introductory level of training (typically of around five days duration) does not equip therapists to practice the Bonny Method, nor any other type of GIM. For that further training is required, with the full training typically taking from three to five years to complete.

Whilst GIM training can be considered a further specialist training for music therapists, it is also, as discussed, a training suitable for credentialed mental health practitioners (Association for Music and Imagery, 2021a) or trained psychotherapeutic practitioners (European Association of Music and Imagery, 2019) who are not musicians and who do not come from a music therapy background. This is because as a receptive method, GIM does not involve active music-making and require the associated music therapy competencies on the part of the therapist as a pre-requisite for GIM training.

Music therapists who go on to train in GIM can legitimately claim it to be part of what they have to offer as music therapists. However, the situation is more complex for those trained in GIM who are not qualified music therapists. To help illuminate the matter, an outline of the situation in the UK is presented next, where the title music therapist is legally protected.

\section{Music Therapy, GIM and State Regulation in the UK Protection of Title and Misuse of Title}

To use the title music therapist, UK-based practitioners are legally required to register with the Health and Care Professions Council (HCPC). This is the government-appointed body that regulates the profession. To apply for HCPC registration in the first place, practitioners must have qualified in music therapy on one of the HCPC approved music therapy MA training programmes which are themselves regulated by the HCPC.

The UK legislation set outs that a person who uses a protected title whilst unregistered commits an offence which is prosecutable if they do so "with intent to deceive (whether expressly or by implication)" (Leglislation.gov.uk, 2002, Article 39[1]). The last clause here means that the HCPC would have concerns and consider using their legal powers if someone did not use the protected title itself but implied it in other ways. An example would be where someone did not advertise using the protected title music therapist but stated in their advert that they offered music therapy (Health and Care Professions Council, 2018a).

On this basis, only those registered as music therapists with the HCPC, and not mental health practitioners from other training backgrounds, may state or imply in advertising their services that they practice music therapy. Anyone else doing this is liable to prosecution.

Thus, UK-based GIM practitioners not additionally qualified in music therapy, and therefore not registered with the HCPC as music therapists, would likely be committing an offence should they use the title music therapist or imply this by stating that they practiced receptive music therapy, for example.

The situation would be similar with practitioners not registered as music therapists who had undertaken training in Therapeutic Songwriting, for example, which is available as a university-accredited training in the UK (UWE Bristol, 2021). On the basis of 
having completed such a training alone, practitioners need to ensure that they do not use the title music therapist or imply it. This is especially important given that training in songwriting is often also incorporated within music therapy training programmes based on its being internationally recognized as a music therapy method (Baker \& Wigram, 2005), with songwriting practiced by many HCPC registered music therapists. The situation is thus potentially confusing for the uninformed public, with the scope of practice of those trained in Therapeutic Songwriting alone, not the same as that of qualified music therapists.

\section{Scope of Practice}

The HCPC defines scope of practice as:

the area or areas of your profession in which you have the knowledge, skills and experience to practise lawfully, safely and effectively, in a way that meets our standards and does not pose any danger to the public or to yourself. (The Health and Care Professions Council, 2018c, Your scope of practice)

Whilst ensuring that music therapists remain within their scope of practice, the HCPC standards of proficiency state that they must:

be able to use a range of music and music-making techniques competently including improvisation, structured musical activities, listening approaches and creation and composition of material and music technology where appropriate and be able to help a service user to work with these. (Health and Care Professions Council, 2018c, 14.20)

\section{Specialisms}

The HCPC recognize that therapist's scope of practice may change over time. Registrants may specialize, developing and extending their skills and knowledge through further training, whilst their general scope of practice may nevertheless narrow:

The practice of experienced registrants often becomes more focused and specialised than that of newly registered colleagues. This might be because of specialisation in a certain area or with a particular client group, or a movement into roles in management, education or research.

Every time you renew your registration, you will be asked to sign a declaration that you continue to meet the standards of proficiency that apply to your scope of practice.

Your particular scope of practice may mean that you are unable to continue to demonstrate that you meet all of the standards that apply for the whole of your profession.

As long as you make sure that you are practising safely and effectively within your given scope of practice and do not practise in the areas where you are not proficient to do so, this will not be a problem. If you want to move outside of your scope of practice, you should be certain that you are capable of working lawfully, safely and effectively. This means that you need to exercise personal judgement by undertaking any necessary training or gaining experience, before moving into a new area of practice. (The Health and Care Professions Council, 2018c, Your scope of practice)

\section{Ensuring Public Protection}

The HCPC's core concern is public protection (The Health and Care Professions Council, 2019). The need for the profession to be regulated to ensure public protection was clarified when the case was originally made for the state registration of the arts therapies including music therapy in the UK parliament:

The profession combines the three disciplines of art, music and drama. All share common approaches to training and practice, but vary in the medium used. All combine artistic proficiency with psychotherapeutic techniques. [...] The therapeutic process can be intense and sustained, and the techniques used are powerful and potentially dangerous to both patient and practitioner if mishandled, particularly where the latter is inappropriately trained or motivated. It is for this reason that members of the professions seek and are 
trained to provide a safe and secure environment in which to help healing. (UK Parliament: Hansard, 1997, column 2028)

As is the case with the arts therapies in general, it has long been recognized that GIM itself is powerful and potentially dangerous for clients if mishandled, with risks that include inducing a psychotic episode, for example (Bruscia, 2015). Therefore, a thorough training is required to ensure therapists practice safely and effectively.

\section{Further Training}

According to the HCPC, registrants should be informed by the advice of their professional bodies in determining the level of knowledge, skill and experience required to practice in a new area and whether further training is required to practice safely and effectively (The Health and Care Professions Council, 2021). Whilst music therapists may actively incorporate "listening approaches" (Health and Care Professions Council, 2018c, 14.20) within their scope of practice at a foundational level (involving one of more of the receptive music therapy methods referred to above that are distinct from GIM), no music therapy training programme in the UK provides full training in GIM.

As discussed above, the specialist competencies (knowledge and skills) required to practice GIM safely and effectively are quite distinct from those acquired from music therapy training, so that further training is needed. Although in the UK GIM training is not itself regulated by the HCPC, there are, as discussed, internationally approved training programmes in GIM, and associated training standards published by the GIM organizations which allow practitioners to acquire the required competencies (Association for Music and Imagery, 2021a; European Association of Music and Imagery, 2019).

\section{The Regulation of the Practice of GIM by the HCPC}

The HCPC would likely be concerned about a music therapist practicing GIM who is untrained in the method. Indeed, the HCPC could potentially consider taking action on the basis of the therapist having failed to meet the HCPC standards of proficiency, working beyond their scope of practice without the training that is internationally recognized to be required, and therefore risking the safety of clients (The Health and Care Professions Council, 2019). Thus, although the HCPC do not regulate GIM training itself, they do effectively regulate the work of music therapists who develop their practice to include GIM as a specialist or advanced level "listening approach" (Health and Care Professions Council, 2018c, 14.20).

\section{Protected and Other Titles}

Whilst HCPC registration carries with it the legal entitlement to use the title music therapist, this does not preclude practitioners from using other titles. These are titles which may be used to indicate a specialism or seniority, for example. The HCPC understands and has no objection to this (HCPC personal communication, February 13, 2013). MI therapist or GIM therapist/counsellor can legitimately be used, for example (HCPC personal communication, September 13, 2021), as can titles which identify accreditation, endorsement, or registration with a GIM organization (see below).

There is also no difficulty in UK music therapists using the title music psychotherapist (HCPC personal communication, February 13, 2013). This may be especially appropriate for those trained in GIM given the internationally recognized psychotherapeutic nature of the method (see below). The British Association for Music Therapy (BAMT) support the use of the title music psychotherapist and publish guidelines about its use for members (British Association for Music Therapy, 2021).

Whatever titles are used, the HCPC standards require registrants to be honest about their experience, qualifications, and skills, and ensure they do not mislead others (The Health and Care Professions Council, 2018b, 9.2 and 9.3). It likely would be of concern to the HCPC should a registrant make unreasonable claims about their skills and 
experience which they could not justify. For example, if they referred to themselves as a specialist when they are not (HCPC, personal communication, February 13, 2013).

\section{Summary of the Rationale for Regulating Music Therapy in the UK}

As a regulator, HCPC's "overarching objectives" (The Health and Care Professions Council, 2019) are to:

- Protect and promote the health and safety of the public

- Protect and uphold public confidence in the professions they regulate

- Set and maintain professional standards and conduct for members of those professions

The need for regulation was elaborated in more detail when the case was originally made for it in the UK parliament:

Essentially, the case for state registration of arts therapists is that it gives a clear and objective signal to the public and to colleagues making referrals. It ensures the high standards of training, conduct and practice that they can expect. The paramount interest is that of patients and carers who will often be in no position to judge the standing of practitioners. They can be assured that both those falsely claiming those standards, and those falling short of them, will be effectively dealt with. In addition, state registration will provide a benchmark for employers; [and] offer an opportunity to strengthen the collaboration between the health professions. (UK Parliament: Hansard, 1997, 2028)

Central to regulation as discussed, is ensuring that practitioners do not mislead others into thinking that they are trained, qualified, experienced, and fit to practice when they are not. The key phrase in the legislation is "intent to deceive (whether clearly or by implication)" (Leglislation.gov.uk, 2002, Article 39[1]).

Whilst there may be no conscious intention to deceive, the public may nevertheless be misled by the way in which therapists describe their work and identify themselves. This is explored further below in considering how some of the principals underpinning the regulation of music therapy in the UK may be helpful in reflecting on the complex relationship between GIM and music therapy in a broader international context.

\section{International Perspectives and the Wider Application of the Principals Underpinning the Regulation of Music Therapy in the UK}

Whilst GIM may be recognized as a music therapy model, it is noteworthy that at the time of writing, the international GIM organizations which endorse, register, or accredit practitioners do not describe GIM as a type of music therapy:

The Bonny Method of Guided Imagery and Music is a music-centered, consciousness-expanding therapy developed by Helen Bonny. Therapists trained in the Bonny Method choose classical music sequences that stimulate journeys of the imagination. Experiencing imagery in this way facilitates clients' integration of mental, emotional, physical and spiritual aspects of well-being. (Association for Music and Imagery, 2021c)

Guided Imagery and Music (GIM) is a psychodynamic and multimodal therapy that incorporates music listening in a deeply relaxed state to stimulate imagery, memories and feelings to help the client understand life issues from a holistic perspective. (Music and Imagery Association of Australia, 2021b)

The Bonny Method of Guided Imagery and Music (GIM) is a music-centred integrative form of psychotherapy. Specifically programmed music is used to facilitate a dynamic exploration of consciousness and inner experiences in support of physical and psychological transformation and well-being. (European Association of Music and Imagery, 2021b)

The titles (designations) that these same organization use for their professional trained members are respectively:

- AMI-endorsed practitioner and Fellow/Facilitator by the Association for Music and Imagery (FAMI) 
- Registered GIM therapist (RGIMT)

- EAMI accredited GIM therapist

In the author's view, these descriptions of GIM and practitioner designations/titles, align with the principals underlying the regulation of music therapy in the UK, and do not imply that GIM therapists are music therapists (even though some may be).

\section{GIM as Psychotherapy}

The European Association of Music and Imagery (EAMI), above, characterise GIM to be a psychotherapeutic method; a music-centred, integrative one. The Music and Imagery Association of Australia (MIAA) describe theirs being "the premier association advancing music psychotherapy in Australia" (Music and Imagery Association of Australia, 2021a). The Korean Association for Music and Imagery (KAMI) similarly refer to GIM as "music psychotherapy" (Korean Association for Music and Imagery, 2021). ${ }^{12}$

It is not only the Bonny Method of GIM that is internationally recognized as a form of psychotherapy or music psychotherapy. Even some supportive MI methods are (Paik-Maier, 2017). However, GIM is not necessarily most appropriately described as psychotherapy in terms of identifying the type of work being undertaken, which may also be oriented towards healing, self-development, and/or spiritual work (Bruscia, 2015). For GIM practitioners in some countries, there may also be legal complications. Thus, for example, around ten European countries have established some form of statutory regulation of psychotherapy (The UK Council for Psychotherapy, 2010). In some of these countries, it may be unlawful for GIM therapists to characterise their work as psychotherapeutic in nature, unless their professional and training background has allowed them to register as psychotherapists (Zanchi, 2021). This is just as in the UK and some other countries, where GIM therapists who are not also registered music therapists may not use or imply the title music therapist.

Whilst international definitions and guidelines are useful, there is also a need to acknowledge how the statutory regulation of professions such as music therapy and psychotherapy affects GIM practitioners in different countries and what the implications are. This is a topic that appears, very understandably, to be a cause of anxiety for some practitioners. National and international guidelines could usefully support practitioners and help inform other professionals, therapy bodies and the public alike, with a recognition that whilst GIM can be identified as a psychotherapeutic method, this is also problematical in some countries from a legal and/or professional perspective.

It is also useful to remember that the term psychotherapy potentially embraces a very wide range of modalities including creative arts-based approaches. In the UK, when the state regulation of the counselling and psychotherapy professions was being considered, for example, it was reported that there were some "400-600 approaches in use" (Health Professions Council, 2009, p. 20).

In helping others understand the unique type of psychotherapy (or music psychotherapy) that GIM is, and correct possible misunderstandings, Bruscia's (1998) work may be a useful starting point. Thus, GIM can be understood to be a transformation-oriented, music-centred form of experiential psychotherapy, where "the therapeutic issue is accessed, worked through, and resolved through [...] listening to music; verbal discourse is used to guide, interpret, or enhance the music experience and its relevance to the client and therapeutic process" (pp. 2-3). This contrasts with the type of insight-oriented "verbal psychotherapy with music" (p. 3) that GIM is not, where "the therapeutic issue is accessed, worked on, and resolved through verbal discourse. Music experiences may be used in tandem, to facilitate or enrich the discussion, but are not considered germane to the therapeutic issue or treatment of it" (p. 3).

In clarifying the nature of psychotherapeutic work in MI and GIM, it is also helpful to bear in mind the different levels of work that can be undertaken, often identified following Wolberg (1977) as supportive, re-educative, and reconstructive (DimiceliMitran, 2020; Grocke \& Moe, 2015; Summer, 2015). 


\section{The Growing Recognition and Integration of GIM as a Specialism Within Music Therapy}

In a 2018 policy statement, the European Music Therapy Confederation (EMTC) strongly recommend that the additional specializations in which already-qualified music therapists may train, where there are published training standards to ensure high quality, be recognized by the national music therapy organizations. The EMTC cite GIM and Neurological Music Therapy as examples of such specialisms. This recognition and recommendation by the EMTC supports the integration and evolving valuing of GIM within music therapy as a specialism, with GIM long identified to be an international model of music therapy practice as discussed (Wheeler et al., 2012).

Cohen (2018) describes GIM to be one of several advanced methods of music therapy practice. She discusses how many music therapists who decide to train in these methods do so later in their careers. She recommends that music therapy training programmes make trainees more aware of the benefits of pursuing additional training in such methods. Her hope is that this may encourage qualified therapists to undertake further training earlier in their careers, helping ensure the continuing development, deepening and expansion of clinical practice in music therapy.

In the author's own experience as a GIM trainer, the increasing availability of separate training in the simpler and increasingly important Music and Imagery (MI) methods within the spectrum of contemporary GIM practice and research (Grocke \& Moe, 2015) seems to appeal to younger therapists and meet their needs as clinicians. MI training is of much shorter duration than the full GIM training. With some training programmes, as discussed, MI training can be undertaken without necessarily needing to complete the full training in GIM to practice MI independently. This kind of training model the author believes to be an especially apt one in supporting the ongoing integration and valuing of GIM within music therapy.

\section{GIM as a Specialization for Mental Health Practitioners who are not Qualified Music Therapists}

In its policy statement, the EMTC (2018) states its intension to foster a culture of inclusion rather than exclusion within music therapy. The EMTC thus strongly recommends that the additional specialist training available for qualified music therapists in modalities such as GIM be formally recognized both nationally and internationally.

What the EMTC does not appear to address in its statement (2018) is the arguably more problematical characterising of GIM to be a type of music therapy by qualified or trainee GIM practitioners who are not also qualified music therapists. This is when the method they practice is identified as GIM Music Therapy, Receptive Music Therapy GIM or similar, with such terms being in current usage in Europe. One of the difficulties with this is that it may mislead clients, other professionals, and the public alike, to assume that practitioners of GIM Music Therapy, for instance, are qualified music therapists when they are not. The UK legislation, as discussed, highlights the need for practitioners to think carefully about the way they identify their work in terms of what they may be implying (Leglislation.gov.uk, 2002, Article 39[1]). It can be suggested that this applies to practitioners in every country, whether or not there be legal implications.

\section{Music Therapy as a Profession}

To clarify the matter further, music therapy training can be identified as being necessary not simply to practice music therapy, but also to become a member of the music therapy profession. In the author's view, public understanding and confidence in the profession would be supported if the term music therapy were solely used by those who have completed a recognized qualification in music therapy in describing what they do. This would include when specialisms are practiced, specifically identified to be types of music therapy. 
Whilst music therapy is a profession, GIM is perhaps best not identified as such, but rather as a specialism in which practitioners from a number of different professions can train. On this basis, a psychologist trained in GIM, even if accredited, endorsed or registered with a GIM organization, does not become a music therapist and thus a member of the profession. Rather, they remain a psychologist by profession, but with a specialism in GIM. This specialism, in the author's view, is best not described as being in a type of music therapy to avoid unnecessarily confusing the public and other professionals about the music therapy profession and who is a qualified member of it.

Similarly, a psychologist trained in Therapeutic Songwriting remains a psychologist but with this specialism. Advertising their services to include music therapy songwriting, for example, would in the author's view be problematical. Whilst the psychologist might argue that songwriting, and GIM if they also practice that, are recognized music therapy methods, the difficulty lies in what may be assumed about the practitioner's professional identity because of their use of the terms music therapy songwriting and receptive music therapy GIM (or similar). Although the specialism(s) may be clearly identified as types of music therapy (and in this sense as not the whole of music therapy), the public may nevertheless assume that the practitioner has a dual professional identity as both psychologist and music therapist. This may in turn generate confusion about who is competent to do what safely and effectively (Muller, 2014), have legal ramifications in some countries, and undermine public confidence in music therapy as a profession (The Health and Care Professions Council, 2019).

With trainings available in GIM, Therapeutic Songwriting and other music-centred therapeutic modalities for those not trained in music therapy, there will, of course, be shared professional competencies with music therapists also trained in these approaches. However, the professional competencies and associated scope of practice of a qualified music therapist are generally much broader, as discussed. The AMI describe the situation thus, referring to the confusion caused with GIM being internationally recognized as a receptive music therapy method/model:

Whether they are musicians or not, training in the Bonny Method does not make a nonmusic therapist a music therapist nor does it qualify them to practice music therapy. This can be confusing because Helen Bonny was a music therapist, and because the Bonny Method has been referred to as a form of music therapy. Bonny Method training certainly does not bestow upon the trainee the professional level of competence in music therapy [...]. At the Professional level, music therapists are trained to create and facilitate a wide variety of clinical music experiences using both live music that is improvised, composed, or recreated by the therapist, and receptive experiences that use live and/or recorded music. (Association for Music and Imagery, 2021b, pp. 7-8)

Whilst the relationship between GIM and music therapy is complex, the point here is that there are alternative ways to identify and describe GIM which are quite adequate, with no need for those who are not music therapists to identify GIM as music therapy. ${ }^{13}$ These other ways to describe GIM are widely used by practitioners (including music therapists), reflect the international GIM organization's descriptions, and have much less potential to mislead.

This may be especially important in countries where the music therapy profession is not regulated. In these countries, the public's understanding of who is and is not a qualified member of the music therapy profession and of who is qualified to do what safely and effectively may well be confused, with individual therapists and organizations needing to give out clear and consistent information to help foster public awareness and confidence (EMTC, 2018).

It may thus be best for GIM practitioners generally, including music therapists, not to name GIM as a music therapy method, but rather describe GIM in its own unique terms. To enable prospective clients to feel confident in GIM as a safe, internationally-recognized, and reputable therapeutic method (or spectrum of methods) in which the practitioner is properly trained and qualified, it is possible to refer to the evidencebase and/or professional membership of a GIM organization. 


\section{Conclusion}

In their policy statement supporting inclusivity and the valuing of specialisms in music therapy, the EMTC (2018) state that "the profession and the associations are more powerful if they work together instead of against each other. The authorities are more apt to listen if the profession speaks with 'one voice"' (p. 1). Related to this and the need to clarify who is trained to do what safely and effectively (Muller, 2014), when the case for regulating the music therapy profession was made in the UK parliament, it was suggested that it would provide "an opportunity to strengthen the collaboration between the health professions" (UK Parliament: Hansard, 1997, column 2028).

The author believes that a collaborative approach involving various national and international GIM and music therapy organizations, including training organizations, may be needed to ensure that the organizations involved do not work against one another as the EMTC imply is in no one's interests and likely to undermine public trust and confidence. Whilst none of these organizations may have the legal authority to dictate how the title music therapist and the term music therapy (and variations on it), are used and by whom, the organizations can nevertheless make informed recommendations that are nationally and internationally consistent and take account of national differences in professional regulation and training. This is where GIM, in a complex and easily misunderstood way, is both part of music therapy and is also separate from it in training, practice, and professionally.

The author's impression is that difficulties may occur when there are apparently conflicting agendas, which may also be able to complement one another to everyone's benefit. Thus, promoting the formal recognition, valuing and integration of GIM within music therapy does not need to conflict with agreeing not to use such terms as GIM music therapy and receptive music therapy GIM because of the potential to confuse. In the author's view, the guidelines recently produced by the AMI (2021b) strike a balance which helps clarify an inherently complex and confusing situation.

Along with the GIM organizations, GIM trainers have an especial responsibility to educate trainees who are not music therapists about the basic differences between music therapy and GIM, and the safe, ethical use of GIM and music therapy titles and designations. The AMI clarifies this in relation its policy advising against non-music therapists referring to themselves as music therapists or to their practices as music therapy:

This draws a clear boundary, and any Trainer who advises their non-music therapist trainees to use the term "music therapy" in advertising their services is going against such advisement and may in doing so be violating the AMI Code of Ethics and Standards of Practice. The same goes for modifications and adaptations of the Bonny Method. The AMI recommends that only music therapists refer to their work as music therapy and thus Trainers who are training non-music therapists should not refer to their trainings as music therapy. (Association for Music and Imagery, personal communication, December 16, 2021)

Finally, although guidelines such as the AMI (2021b) have provided are potentially important for practitioners in promoting consistent, ethical practice, what may be most important for the public is not introducing confusion unnecessarily where this can be avoided. What is not stated may be as important as what is. In this sense, the problems identified in this article may be able to be avoided simply if practitioners elected not to describe GIM as music therapy in advertising services or training.

In summary, it is proposed the following be considered as the basic principles to inform further discussion:

1. Music therapy training and GIM training are distinct.

2. The professional competencies and scope of practice of music therapists and of GIM therapists are also distinct (unless the music therapist is also trained in GIM).

2.1. Music therapists are qualified in a broad range of active and receptive methods but tend predominantly to use active approaches. 
2.2. The various receptive music therapy methods practiced by music therapists (not additionally trained in GIM) need to be differentiated from GIM itself. In this sense, receptive music therapy and GIM are best distinguished to avoid confusion.

2.2.1. In particular, Music and Imagery as practiced by music therapists (not additionally trained in GIM) needs to be differentiated from MI as developed and practiced by GIM therapists.

2.2.2. There is a general confusion and inconsistency around the use of terms in GIM, with the boundaries between different types of practice unclear:

Without clarification of these boundaries who knows who is trained to do what? Who knows what practices are potentially harmful and what training is needed to practice them safely? (Muller, 2017, p. 44)

3. Music therapy is a profession. GIM training alone does not qualify practitioners as music therapists and thus as members of the music therapy profession. GIM training is not a training in music therapy in this important sense.

4. GIM is best understood not as a profession, but as a specialism (of advanced-level practice) in which qualified members of various professions can train including music therapy, psychology, psychotherapy, and psychiatry.

4.1. When GIM is identified as a type of music therapy by members of other professions in advertising their services, the public may assume that these other professionals are also qualified music therapists. This has the potential to create confusion about the music therapy profession, about who is and is not a qualified music therapist, and about who is qualified to do what safely and effectively.

4.1.1. The misunderstanding generated may undermine public trust and confidence in both music therapy and in GIM as a specialism. This is likely to be especially so when there is an inconsistency of approach amongst different individuals and organizations within a country.

4.1.2. GIM can be effectively identified and described in other ways.

4.1.3. The term Guided Imagery and Music in any language and however translated needs explanation so that prospective clients and others can properly understand the nature of GIM as part of informed consent. ${ }^{14}$ Using such terms as GIM Music Therapy and Receptive Music Therapy GIM may confuse more than clarify.

4.1.4. There may be legal consequences in some countries.

4.2. Whilst GIM can be identified as a psychotherapeutic method, its musiccentred nature needs clarifying, associated with the way it differs from verbal psychotherapy. This is especially important where in some countries characterising GIM as psychotherapy may be problematical for practitioners who are not legally registered psychotherapists.

4.2.1. Different levels of psychotherapeutic work can be undertaken in GIM (supportive, re-educative and reconstructive) with the work alternatively oriented towards healing, self-development and/or spiritual development.

5. Promoting the valuing and integration of GIM as an evidence-based specialism for music therapists does not need to conflict with clarifying the distinction between GIM and music therapy, in training, practice, competencies, and professionally.

6. When GIM training is characterised as being in a type of music therapy, prospective trainees may assume that they will become music therapists once qualified. 
Links with music therapy need to be very carefully made so that they do not confuse and create misunderstanding. Trainers have an especial responsibility in this.

The author is sympathetic with the arguments of those who promote GIM and training in it as training in music therapy. However, until such time as GIM training alone is internationally agreed to constitute a training that qualifies practitioners as music therapists, the author considers that a consensus agreement aligned with the guidelines recently published by the AMI (2021b) would be in the best interests of clients, the public, practitioners, the music therapy profession and the GIM community.

It is in any case perhaps unlikely that there will ever be international agreement that GIM training alone qualifies counsellors, psychologists, psychotherapists, and others as music therapists ${ }^{15}$. This is for all the reasons set out above. GIM is likely to remain both part of, and separate from music therapy, the GIM community similarly. The irreducible complexity and paradox of this needs to be embraced and clarified in the author's view. It is this that is most likely to foster the ongoing integration of GIM within music therapy in a way that is not controversial and can be understood and accepted by all.

\section{About the Author}

Martin Lawes is a UK-based music therapist additional trained in Guided Imagery and Music (GIM). He is endorsed as a GIM trainer by the Association for Music and Imagery (AMI) and is founder of the Integrative GIM Training Programme which offers online and in-person training. He has published about GIM in four peer-reviewed journals. Martin was former chair of both the board and education committee of the European Association of Music and Imagery (EAMI) and has served on the AMI Standards committee. Martin has a special interest in the culture and ethics of GIM and its organizations and is part of an independent think-tank set up to explore this. Along with others, he provides independent GIM ethics consulting and support for those who have concerns.

\section{Notes}

1. Whilst the GIM Training Standards published by the AMI (2021b) are exclusively for training in the Bonny Method of GIM, the competencies for professional practice require therapists to be able to "utilize adaptations and modifications of the GIM process according to client need" (Competency 11.5, p. 9). The EAMI Training Standards (2019) cover training in the Bonny Method of GIM as well as in adaptations and modifications, described as a spectrum of methods including other GIM and MI methods (pp. 3-7). Thus, both AMI-endorsed and EAMI-accredited GIM therapists may include a spectrum of approaches including MI in their work, GIM therapist a generic term in the way it is often used.

2. Whilst the author has attempted to provide clarity in relation to his own use of terms, the situation is a complex and indeed confusing one in the way different terms and definitions are used in the literature. GIM may, for example, sometimes be used as a generic term and sometimes be used to refer specifically to the Bonny Method of GIM. Used as a generic term, MI may or may not be included as part of GIM and this not always be clear. In relation to adaptations and modifications of the Bonny Method of GIM, Grocke and Wigram (2007) use a different set of terms to Grocke and Moe (2015). Bruscia (2015), in defining various types of practice, uses another set of terms. As a starting point, Bruscia (2002, 2015) and Muller (2014) have sort to define the core components of the Bonny Method of GIM as originated by Bonny and discuss adaptations and modifications in relation to these. Other practitioners, the author included, do not consider it necessary to define the Bonny Method so precisely in relation to contemporary practice (Grocke, cited in Montgomery, 2015), suggesting it may confuse as much as clarify (Lawes, 2017). In a recent publication, Grocke (2019), as editor, refers to the continuing dilemma of naming the method where the authors of the individual chapters in the publication were encouraged to clarify their use of such terms as GIM and MI, there being no internationally agreed consensus. Practi- 
tioners who have developed specific GIM or MI methods or models may also use their own bespoke names for these as discussed in the main text (Booth, 2010; Dimiceli-Mitran, 2020; Körlin, 2019; Summer, 2015; Wärja, 2015).

In the case of MI, the situation is especially complex. Not only do the US music therapy competencies include those in "music and imagery" (American Music Therapy Association and Certification Board for Music Therapists, 2015), but MI Standards are being developed in Europe which, it appears, may potentially include two different levels of entry requirement for different methods (Frohne-Hagemann, 2021). There is also the work of Radulović (1996), a Serbian music therapist not trained in GIM who has developed the Guided Fantasies Method. This is used in groupwork and described as "a technique from the domain of the receptive, reconstructive music therapy of the transpersonal range" (Radulovic, 2010, p. 11). The Bonny Method of GIM in its group form could potentially be described similarly (Bruscia, 2015).

All the above makes the situation a confusing one for the public as well as for the music therapy and GIM communities, and for other professionals. The author is aware of no publication that embraces the contemporary spectrum of practice in its full diversity, with an inconsistent and confusing use of terms amongst the different publications as discussed. What is more, in discussing and presenting about their work, different practitioners may use the same term, MI, for example, to refer to different methods and different levels of work. Thus, MI may on the one hand involve the client imaging to music in an altered state of consciousness, or on the other hand involve the client drawing whilst listening to music. A practitioner may use the term MI to refer exclusively to supportive level work, or they may include re-educative and reconstructive level work in addition.

The author would strongly recommend international discussion to agree on a consensus position related to the use of terms by those trained in GIM and/or MI, that embraces the full spectrum of contemporary practice globally, and provides clarity rather than confusion for others. Muller (2017) makes a similar recommendation, highlighting the importance of clarifying boundaries and who is trained to do what safely and effectively.

3. Summer (2015) in her terminology draws on Wolberg's (1977) three levels of psychotherapy-supportive, re-educative and reconstructive.

4. Focused Music Imaging (FMI) is a hybrid method where the client experiences a brief period of mental imaging in a relaxed state with the music playing, the experience structured by the therapist using a talk-over, before the drawing or writing begins whilst the music continues to play (Dimiceli-Mitran, 2020).

5. In the Bonny Method of GIM, in contrast, the therapist needs to select the music programme used, the client not being in a position to choose as this requires a sophisticated familiarity with the music programmes and their potential in the work. The process is, nevertheless, a deeply collaborative one in the way the client is supported to engage in a highly personal, specific, intimate, and creative experience of the music provided according to their needs (Lawes, 2016).

6. The EAMI currently require applicants for GIM training to have already received a substantial psychotherapeutic education, one that included supervised client work and a self-experience component (equivalent to sixty European Credit Transfer and Accumulation System [ECTS] points or 1,500 to 1,800 hours). In addition, applicants must have a minimum of two years post-qualification experience working psychotherapeutically before commencing GIM training (or at least before commencing supervised client work during training). The psychotherapeutic modalities and associated professions accepted by the EAMI, in which applicants for GIM training may have received their psychotherapeutic education, include mental health counselling, music therapy, the other creative arts therapies, body psychotherapy and verbal psychotherapy (European Association of Music and Imagery, 2019).

7. The AMI (Association for Music and Imagery, 2021b), in discussing what is meant by "credentialed mental health practitioner" (as required on p. 12), alternatively described as a "professional practitioner in the helping relations field" (as recommended on p. 14), leave the matter open in terms of the competencies and associated training that may be required, 
the individual trainer and trainee to agree this. In giving examples, the Training Standards refer to the possibility of a trainee having acquired, or acquiring during training, "professional qualifications as a music therapist, psychotherapist, psychologist, spiritual director, etc." (p. 12).

The EAMI Training Standards (2019) in contrast, clarify the specific psychotherapeutic competencies required before commencing GIM training (see note 6). The emphasis on psychotherapy seems to reflect the nature of much of the work carried out in Europe in clinical settings, where a spectrum of different methods may be employed which the Training Standards also embrace (Bonde, 2017; Moe \& Lund, 2017). There is, however, ongoing discussion about the merits of, and problems associated with, defining GIM as psychotherapy in Europe (European Association of Music and Imagery, 2021a).

The AMI do not define GIM to be psychotherapeutic in nature, the AMI Training Standards (Association for Music and Imagery, 2021b) also differing from those of the EAMI in being exclusively concerned with training in the Bonny Method of GIM. The suggestion of a spiritual director potentially being able to qualify in GIM, seems to encompass an understanding of the Bonny Method not simply being a modality of psychotherapeutic work, but also/alternatively a modality of healing, self-development, and/or spiritual exploration (Bruscia, 2015).

In the author's view, a difficulty with the AMI's more open, flexible approach to what is required for training, relates to the method being a powerful one with considerable risks for the client in an altered state of consciousness, whatever the orientation of the work is intended to be. Preventing, recognizing, and properly handling these risks is of vital importance in terms of safe and ethical practice (Bruscia, 2015). It is in relation to this that, arguably, psychotherapeutic competencies (and previous clinical experience) should be required of all those who intend to train in GIM (where the specifics of this could nevertheless potentially be clarified avoiding the word psychotherapy given the difficulties this causes in some countries). Alternatively, more extensive GIM trainings could be developed for practitioners without a suitable training background to impart the necessary foundational competencies (Grewe, 2021).

The EAMI has recently begun to consider that the psychotherapeutic prerequisites for training in GIM and MI set out in its Training Standards (European Association of Music and Imagery, 2019) may not be required for training in "low threshold" forms of MI. It is, however, also recognized that this is potentially risking client safety because "inexperienced practitioners can easily get overwhelmed by a client's suddenly emerging repressed conflicts or by his or her traumatic experiences that are breaking through. And it is too short thought to advise the client in such a situation to find a psychotherapist (what if no one is available?) and who helps the practitioner in the situation?" (Frohne-Hagemann, 2021, pp. 4-5).

In view of the serious nature of the risks involved for both clients and therapists when the latter is insufficiently well trained (Bruscia, 2015; UK Parliament: Hansard, 1997, column 2028), the author strongly suggests that the requirements to train in both MI and GIM be discussed internationally so as to agree a consensus position which is clear, unambiguous and consistent between the organizations, and can be tied to an agreed use of terms and associated clarification about who is trained to do what safely and effectively (Muller, 2017).

8. See note 1 .

9. The situation is, of course, variable dependent on the country. In the former East Germany, for example, Schwabe's "Regulative Music Therapy" (Frohne-Hagemann, 2007; Voigt, 2010), a receptive music therapy approach, was one of the most important methods taught. Following unification, because a tradition of receptive music therapy practice had been established in East Germany, the full GIM training became accepted as a postgraduate training in music therapy by the German Music Therapy Association. This was for those already qualified in music therapy, psychotherapy, psychiatry, art therapy, etc. Thus in Germany, a licenced psychotherapist with additional training in GIM but not in other kinds of music therapy could call themself a music therapist (music therapy not regulated by law in the 
country in any case). This possibility resulted from the unique way music therapy had evolved in the country where open discussion in the German music therapy associations took place to come to an agreement about the matter (Dr. Carola Maack, personal communication, January 16, 2022). Whilst the organizations in any country could potentially come to such an agreement, for the reasons explored in the article the author considers that GIM training alone is generally best not identified as a training in music therapy. It is in any case unlikely that there will ever be international agreement about the matter given the legal situation in some countries as discussed. Furthermore, even in Germany, active music therapy approaches are the ones most often used in contemporary practice (Deutsche Musiktherapeutische Gesellschaft, 2022), the competencies needed for this distinct from the specialist, advanced level competencies required to practice GIM.

10. See note 7.

11. The Appalachian State University in the US provides the full GIM training which may be undertaken as part of the Master in Music Therapy degree, which in the US constitutes advanced-level training in music therapy (Appalachian State University, 2022). Level I is required for the MMT, but students have the option of specializing in GIM and may complete GIM training as a substantial part of their course plan. The full GIM training is rarely completed in full before the student finishes the Masters, but it is all offered within the university's music therapy training program (Tim Honig, personal communication, February 4, 2022).

12. The Korean Association for Music and Imagery (KAMI) does not endorse, register, or accredit practitioners, its members AMI-endorsed practitioners. KAMI does, nevertheless, publish a Code of Ethics and grievance procedure (Jung Pyo Moon, KAMI President, personal communication, September 17, 2021).

13. It can be added here that the public are unlikely to understand the nature of GIM without clear explanation. The term Guided Imagery and Music itself, whether in English or translated, does not explain what the method involves. Prospective clients may indeed be misled by the associations they have with the individual words 'guided' and 'imagery,' and with the phrase 'guided imagery,' for example. The uninformed public are likely to have little if any understanding of what imagery means in GIM, and that GIM involves listening to recorded music in an altered state. Even if they do understand this, they may assume that the method involves directive rather than non-directive guiding. All this and more needs to be explained, so that potential clients can make an informed choice whether to try GIM.

14. See note 13.

15. See note 9 .

\section{References}

American Music Therapy Association (AMTA) and Certification Board for Music Therapists (CBMT) (2015). Scope of music therapy practice. https://www.musictherapy.org/assets/1/7/ CBMT_AMTA_Scope_of_Music_Therapy_Practice.pdf

Appalachian State University. (2022). Music Therapy: The Master of Music Therapy Degree: Training in the Bonny Method of Guided Imagery and Music (GIM).

https://musicgraduate.appstate.edu/programs/16

Association for Music and Imagery. (2005). Bonny Method Resources. Spring 2005 newsletter, 18(2).

Association for Music and Imagery. (2021a). AMI, competencies, training program standards, and procedures for the Bonny Method of GIM (Revised November 4, 2021; Effective Dec. 1, 2021).

Association for Music and Imagery. (2021b). Bonny Method Resources. Fall 2021 newsletter, $34(2)$.

Association for Music and Imagery. (2021c). Frequently asked questions: What is the Bonny Method?. https://ami-bonnymethod.org/index.php/about/faq 
Baker, F., \& Wigram, T. (Eds.). (2005). Songwriting: Methods, techniques and clinical applications for music therapy clinicians, educators and students. Jessica Kingsley Publishers.

Bonde, L. O. (2015). The Bonny Method of Guided Imagery and Music (GIM) in Europe. Approaches: Music Therapy \& Special Music Education, Special Issue 7(1), 86-90. https://approaches.gr/wp-content/uploads/2015/08/ 10-Approaches_712015_Bonde_Article.pdf

Bonde, L. O. (2017). The future of the Bonny Method: A perspective on Danish practice with a forecast to the future. Approaches: An Interdisciplinary Journal of Music Therapy, Special Issue 9(2), 300-305. https://approaches.gr/wp-content/uploads/2017/12/

9-Approaches-9-2-2017-bonde-a20171222.pdf

Booth, J. (2010). Music, Drawing, and Narrative: An adaptation of the Bonny Method of Guided Imagery and Music. Journal of the Association for Music and Imagery, 10, 55-74.

British Association for Music Therapy. (2021). Guidelines on professional titles for music therapists.

Bruscia, K. E. (1998). An introduction to music psychotherapy. In Bruscia, K. E. (Ed.), The dynamics of music psychotherapy (pp. 1-16). Barcelona Publishers.

Bruscia, K. E. (2002). The boundaries of Guided Imagery and Music and the Bonny Method. In K. Bruscia and D. Grocke (Eds.), The Bonny Method and beyond (pp. 37-62). Barcelona Publishers.

Bruscia, K. E. (2015). Notes on the practice of Guided Imagery and Music. Barcelona Publishers.

Cohen, N. S. (2018). Advanced methods of music therapy practice: Analytical music therapy, the Bonny Method of Guided Imagery and Music, Nordoff-Robbins music therapy, and vocal psychotherapy. Jessica Kingsley Publishers.

Deutsche Musiktherapeutische Gesellschaft (DMtG). (2022). Was ist musiktherapie?. https://www.musiktherapie.de/musiktherapie/was-ist-musiktherapie/

Dimiceli-Mitran, L. (2020). Focused Music Imagery (FMI): Pathway through the psyche, supportive and re-educative case examples. Journal of the Association for Music and Imagery, 17, 37-54.

European Association of Music and Imagery. (2019). The European Association for Music and Imagery (EAMI) Standards for Training in Guided Imagery and Music (GIM). Re-revised version 07.08. 2019.

European Association of Music and Imagery. (2021a). Newsletter, June 2021.

European Association of Music and Imagery. (2021b). What is GIM?. https://www.music-andimagery.eu/what-is-gim

European Music Therapy Confederation (EMTC) (2018). Statement of Policy, September 9, 2018.

Fincher, S. (2010). Creating Mandalas for insight, healing and self-expression (Revised ed.). Shambhala Publications.

Frohne-Hagemann, I. (Ed.) (2007). Receptive music therapy - Theory and practice. Reichert Verlag.

Frohne-Hagemann, I. (2021). Presentation from the European Association of Music and Imagery (EAMI) members meeting, September 25, 2021:Definitions and the German situation. European Association of Music and Imagery.

Fuglestad, S. (2019). The development of music programs in Europe and beyond. In D. E. Grocke (Ed.), Guided Imagery and Music: The Bonny Method and beyond (2nd ed., pp. 591-608). Barcelona Publishers.

Grewe, G. (2021). Presentation from the European Association of Music and Imagery (EAMI) members meeting, September 25, 2021. European Association of Music and Imagery.

Grocke, D. E. (2019a). Appendices: Music programs developed by GIM practitioners. In D. E. Grocke (Ed.), Guided Imagery and Music: The Bonny Method and beyond (2nd ed., pp. 837-848). Barcelona Publishers.

Grocke, D. E. (2019b). Helen Bonny's music programs. In D. E. Grocke (Ed.), Guided Imagery and Music: The Bonny Method and beyond (2nd ed., pp. 72-102). Barcelona Publishers. 
Grocke, D., \& Moe, T. (Eds.) (2015). Guided Imagery \& Music (GIM) and music imagery methods for individual and group therapy. Jessica Kingsley Publishers.

Grocke, D., \& Wigram, T. (Eds.) (2007). Receptive methods in music therapy: Techniques and clinical applications for music therapy clinicians, educators and students. Jessica Kingsley Publishers.

Korean Association for Music and Imagery. (2021). Home. http://www.gimkorea.or.kr/

Körlin D. (2019). Music breathing. In D. E. Grocke (Ed.), Guided Imagery and Music: The Bonny Method and beyond (2nd ed., pp. 652-679). Barcelona Publishers.

Lawes, M. J. (2016). Perspectives on the real, the imaginary and the music in GIM. Journal of the Association for Music and Imagery, 15, 93-124.

Lawes, M. (2017). Book review: "Variations in Guided Imagery and Music: Taking a closer look" (Bryan Muller). Approaches: An Interdisciplinary Journal of Music Therapy, Special Issue9(2), 375-381. https://approaches.gr/wp-content/uploads/2017/12/

17-Approaches-9-2-2017-lawes-br20171222.pdf

Leglislation.gov.uk. (2002). The Health Professions Order 2001: UK Statutory Instruments 2002 (254). https://www.legislation.gov.uk/uksi/2002/254/contents/made

Moe, T., \& Lund, S. T. (2017). In search of the lost grail: An interview with Torben Moe. Approaches: An Interdisciplinary Journal of Music Therapy, Special Issue9(2), 359-366. https://approaches.gr/wp-content/uploads/2017/12/15-Approaches-9-2-2017-moei20171222.pdf

Montgomery, E. (2015). An Interview with Denise Grocke: Discussing GIM and its adaptations. Voices: A World Forum for Music Therapy 15(2). https://voices.no/index.php/voices/article/ view/2277

Muller, B. (2014). Variations in Guided Imagery and Music: Taking a closer look. Barcelona Publishers.

Muller, B. (2017). Guided Imagery and Music: A survey of current practices. In Research Symposium Proceedings, 24th International Association for Music \& Imagery Conference, June 14-17, 2017 (pp. 40-45). http://ami-bonnymethod.org/images/uploads/articles/ 2017_Research_Symposium_Bryan_Muller.pdf

Music and Imagery Association of Australia. (2020). Code of ethics, standards of practice, and by-laws. http://www.musicandimagery.org.au/uploads/4/9/0/6/4906406/ miaa_code_of_ethics_version_4_2020.pdf

Music and Imagery Association of Australia. (2021a). Home.

http://www.musicandimagery.org.au/

Music and Imagery Association of Australia. (2021b). What is GIM?.

http://www.musicandimagery.org.au/what-is-gim.html

Ng, W. M. (2019). Chinese GIM music programs. In D. E. Grocke (Ed.), Guided Imagery and Music: The Bonny Method and beyond (2nd ed., pp. 560-574). Barcelona Publishers.

Paik-Maier, S. (2017). An exploratory study of the processes of Supportive Music and Imagery therapy conducted in South Korea [Doctoral dissertation, The Tavistock and Portman Foundation and the University of East London]. Tavistock and Portman repository. http://repository.tavistockandportman.ac.uk/1798/1/PaikMaier\%20\%20-\%20An\%20exploratory.pdf

Radulovic, R. (1996). The using of music therapy in treatment of depressive disorders [Master Thesis, University of Belgrade]. https://www.wfmt.info/Musictherapyworld/modules/ archive/dissertations/pdfs/Master_Radulovic_1996.pdf

Radulovic, R. (2010). Qualitative analysis of the Analytical Music Listening (ALM) music selection - The Guided Fantasies Method (GFM). Book of abstracts and programme for the VIII European music therapy congress: Evidence for music therapy research, practice \& education, Cadiz (Spain) May 5-9, 2010. https://www.academia.edu/764454/

Evidence_for_Music_Therapy_Practice_Research_and_Education_Book_of_Abstracts_and_ Programme_of_the_VIII_European_Music_Therapy_Congress 
Summer, L. (2015). The journey of GIM training from self-exploration to a continuum of clinical practice. In D. Grocke \& T. Moe (Eds.), Guided Imagery \& Music (GIM) and Music Imagery methods for individual and group therapy (pp. 339-348). London: Jessica Kingsley.

The Health and Care Professions Council. (2018a, June 29). Misuse of title. https://www.hcpcuk.org/concerns/what-we-investigate/misuse-of-title/

The Health and Care Professions Council. (2018b, June 14). Standards of conduct, performance and ethics. https://www.hcpc-uk.org/standards/standards-of-conduct-performance-andethics/

The Health and Care Professions Council. (2018c, June 29). The standards of proficiency for arts therapists. https://www.hcpc-uk.org/standards/standards-of-proficiency/arts-therapists/

The Health and Care Professions Council. (2019, January 14). What we investigate: registered professionals. https://www.hcpc-uk.org/concerns/what-we-investigate/registeredprofessionals/

The Health and Care Professions Council. (2021, March 25). FAQs and resources: I'm thinking about moving into a new scope of practice. What do I need to do?. https://www.hcpc-uk.org/ standards/meeting-our-standards/scope-of-practice/what-is-your-scope-of-practice/faqs-andresources/

The Health Professions Council. (2009). The statutory regulation of psychotherapists and counsellors: Responses to the consultation on the recommendations of the Psychotherapists and Counsellors Professional Liaison Group (PLG). Health Professions Council.

The UK Council for Psychotherapy. (2010). Working as a psychotherapist in Europe. The Psychotherapist, UKCP magazine, Winter2010-2011 (pp. 39-40). http://psychotherapycompetency.eu/Documents/Working_as_a_psychotherapist_in_Europe.pdf.

UK Parliament: Hansard. (1997). Professions Supplementary to Medicine (Arts Therapists Board) Order of Council 1997. https://hansard.parliament.uk/Lords/1997-03-06/debates/ bb4ce259-5673-420c-a5b9-e7d87d6242d9/

ProfessionsSupplementaryToMedicine(ArtsTherapistsBoard)OrderOfCouncil1997

UWE Bristol. (2021). Therapeutic songwriting. University of the West of England (UWE). https://courses.uwe.ac.uk/USPKJC15M/therapeutic-songwriting\#entry

Voigt, M. (2010). Interview with Christoph Schwabe. Voices: A World Forum for Music Therapy, 10(1). https://doi.org/10.15845/voices.v10i1.322

Wärja, M. (2015). KMR (Short Music Journeys) with women recovering from gynecological cancer. In Grocke, D., \& Moe, T. (Eds.), Guided Imagery \& Music (GIM) and Music Imagery methods for individual and group therapy (pp. 253-266). Jessica Kingsley Publishers.

Wheeler, B., Wagner, G., Summer, L., Madsen, C., Turry, A., \& Eschen, J. (2012). Five international models of music therapy practice. Voices: A World Forum for Music Therapy, 12(1). https://doi.org/10.15845/voices.v12i1.634

Wolberg, L. R. (1977). The Technique of Psychotherapy (3rd ed., part 1). Grune and Stratton.

Zanchi, B. (2021). Presentation from the European Association of Music and Imagery (EAMI) members meeting, September 25, 2021. European Association of Music and Imagery. 